\title{
NET ACCUMULATION AND OXYGEN ISOTOPE COMPOSITION OF SNOW ON MIZUHO PLATEAU, ANTARCTICA
}

by

\section{KazUHide SATOW}

Nagaoka College of Technology, Nagaoka, Japan

OKITSUgu Watanabe

Water Research Institute, Nagoya University, Nagoya, Japan

\section{ABSTRACT}

Characteristics of annual net accumulation were studied in time and space in Mizuho Plateau, Antarctica. Annual variation of net accumulation was obtained from 1914 to 1981 from the analysis of a $30 \mathrm{~m}$ core bored in a high accumulation zone. Power spectral analysis of the annual accumulations shows two predominant periodicities, one of 45 years, and the other of 18 years.

Inland, with small accumulation and strong temperature gradient at the surface, developments of depth hoar and the metamorphism of oxygen isotope composition $\left(\delta^{18} \mathrm{O}\right)$ profile of snow take place near the snow surface. From experimental results, the authors propose some models of the metamorphism of $\delta^{18} \mathrm{O}$ profile of snow with temperature gradient. These models can be divided into two groups: one where a cap, such as an ice crust, is present, and the other without.

\section{INTRODUCTION}

Based on snow accumulation data acquired by Japanese Antarctic Research expeditions, Mizuho Plateau is usually divided into three different accumulation zones: a high accumulation zone, about $2000 \mathrm{~m}$ a.s.l. and lower; an

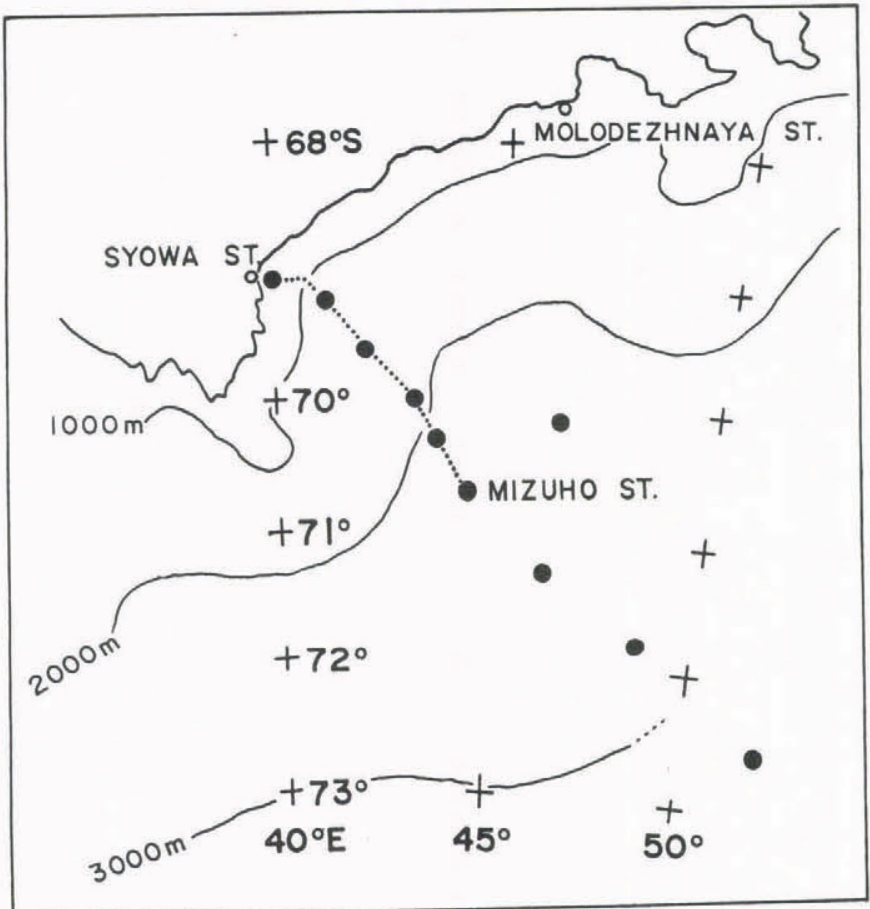

Fig.1. Study area on Mizuho Plateau, Antarctica. Solid circles show 36-stake farms, and the dashed line is the traverse route where net accumulations were obtained at 2 $\mathrm{km}$ intervals by stake height measurements. irregular accumulation zone, between $2000 \mathrm{~m}$ and $3000 \mathrm{~m}$ a.s.1.; and a low but uniform accumulation zone, 3000-3200 m a.s.l. and higher (Watanabe 1978a; Yamada and Wakahama 1981). This paper describes some characteristics of net snow accumulation measured by stake method, the variation of annual net accumulation obtained through firn core analysis, and some problems in determining each annual layer by oxygen isotope composition. The study area is shown in Figure 1.

CHARACTERISTICS OF SNOW ACCUMULATION ON MIZUHO PLATEAU

The scatter of annual net accumulations at a given place

36 stakes spaced $10 \mathrm{~m}$ apart was set up in a square pattern at ten different places between $550 \mathrm{~m}$ and $3100 \mathrm{~m}$ a.s.l. on the Mizuho Plateau. The purpose of this stake-farm method was to obtain reliable representative values at each place, and also to examine the scatter of 36 annual net accumulations at each place. Figure 2 shows that the

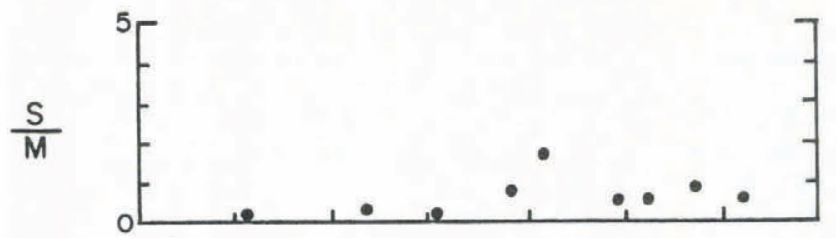

S
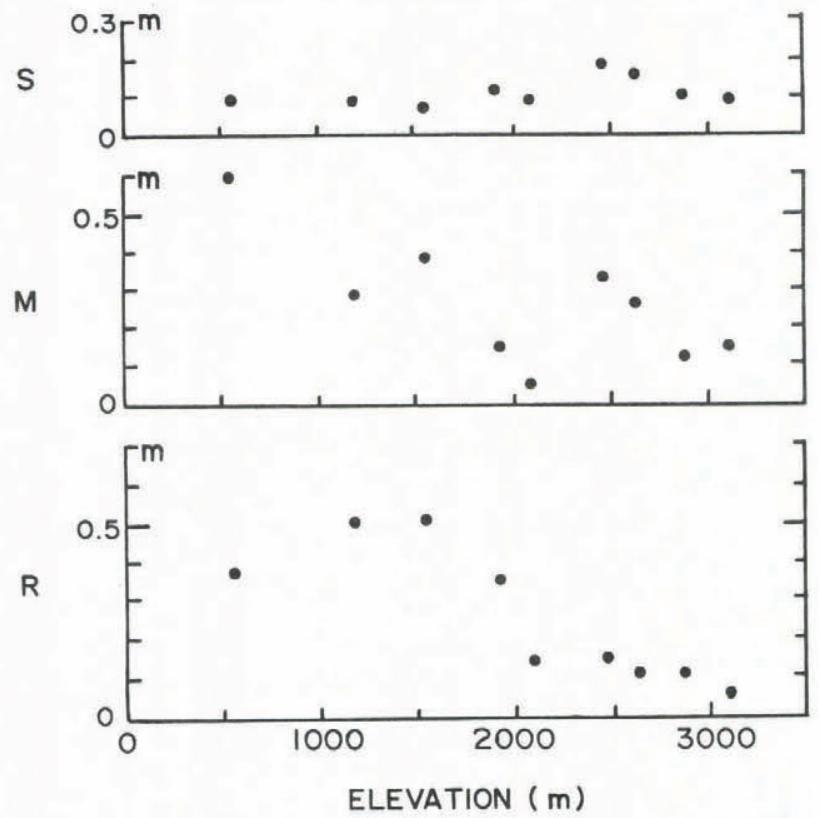

Fig.2. Roughness of snow surface $R$; average of thirty-six values of annual accumulation $\mathrm{M}$ in 1981 (m of snow depth); standard deviation $\mathrm{S}$ of the thirty-six values; and coefficient of variation $S / M$, plotted against elevation of 36-stake farms (after Satow 1984). 
coefficient of variation $\mathrm{S} / \mathrm{M}$, where $\mathrm{M}$ is the average of 36 values of annual accumulation in 1981 and $S$ is the standard deviation, was small (less than 1.0) especially in the high accumulation zone. Besides, the value of $\mathrm{S} / \mathrm{M}$ did not depend on the roughness of snow surface (Satow 1984).

Average of annual net accumulation during the period from $1968 / 72$ to 1981

From data of annual net accumulations measured by single stake method in 1968/72-1981, the averages of annual accumulations were obtained at $2 \mathrm{~km}$ intervals along the

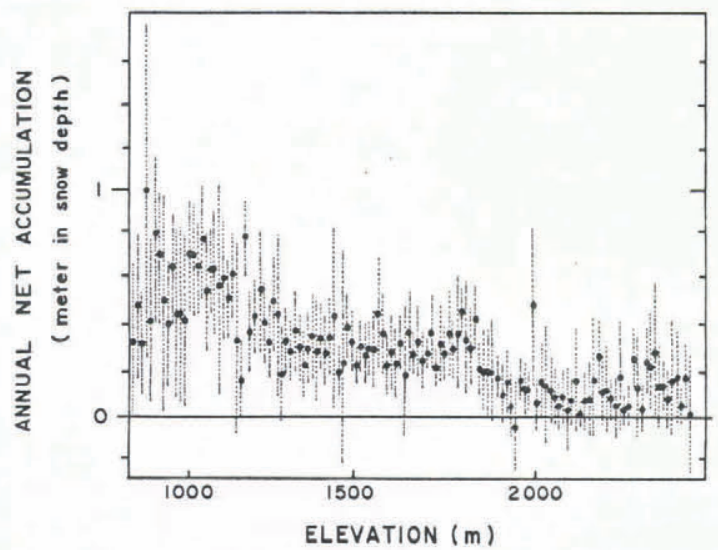

Fig.3. Average annual net accumulations $1968 / 1972$ to 1981 against elevation, along the traverse route (dashed line in Fig.1) on Mizuho Plateau. Dashed vertical lines denote standard deviations for the same period.

traverse routes in the area between $550 \mathrm{~m}$ and $2230 \mathrm{~m}$ a.s.1.. Figure 3 shows that annual net accumulation is higher (0.4-0.8 m per snow depth/year) near the coastal region (as far as about $160 \mathrm{~km}$ from the coast), which is strongly influenced by low pressure activities, and decreases inland.

Analysis of a $30 \mathrm{~m}$ core in a high accumulation zone

Glaciological studies of a $30 \mathrm{~m}$ firn core were carried out at Station S18 in the coast area near Syowa Station, where annual net accumulation was assumed to be about 0.5 $m$ snow depth a year. The features of profiles of density, depth hoar level (Watanabe 1978b), oxygen isotope composition $\left(\delta^{18} \mathrm{O}\right)$ and stratigraphy of the core indicate that there are no great difficulties in determining annual layers, and thus in obtaining a year-by-year dating of the core. A part of the core analysis is shown in Figure 4. In this way, the annual variation of snow accumulations at the station was obtained from 1914 to 1981 (Figure 5). It was found that annual net accumulations were higher during the period between 1947 and 1960 .

Power spectrum analysis was made of layer-to-layer variations of annual accumulations of the core. Then the power spectrum was computed by applying the mximum entropy method (MEM) developed by J.P. Burg (Hino 1977). In the power spectrum as shown in Figure 6 , two most prominent peaks indicate periodicities of 45 years and 18 years. At present the relation is unclear between these periodicities of accumulation and variations of other meteorological factors such as pressure, temperature and wind speed.

RELATIONS BETWEEN SNOW ACCUMULATION AND OXYGEN ISOTOPE COMPOSITION $\left(\delta^{18} \mathrm{O}\right)$ OF SNOW $\delta^{18} \mathrm{O}$ profile against depth

The $\delta^{18} \mathrm{O}$ profile (Figure 4) shows typical seasonal variations, providing a useful method of determining annual snow layers. But further inland the profile becomes more complicated and does not ususally show much seasonal variation (Watanabe and others 1981). This is thought to be connected with the snow accumulation depth, the season of surface formation by deposition-erosion process and snow metamorphosis, such as depth hoar formation. Inland the difference of mean monthly temperatures between summer

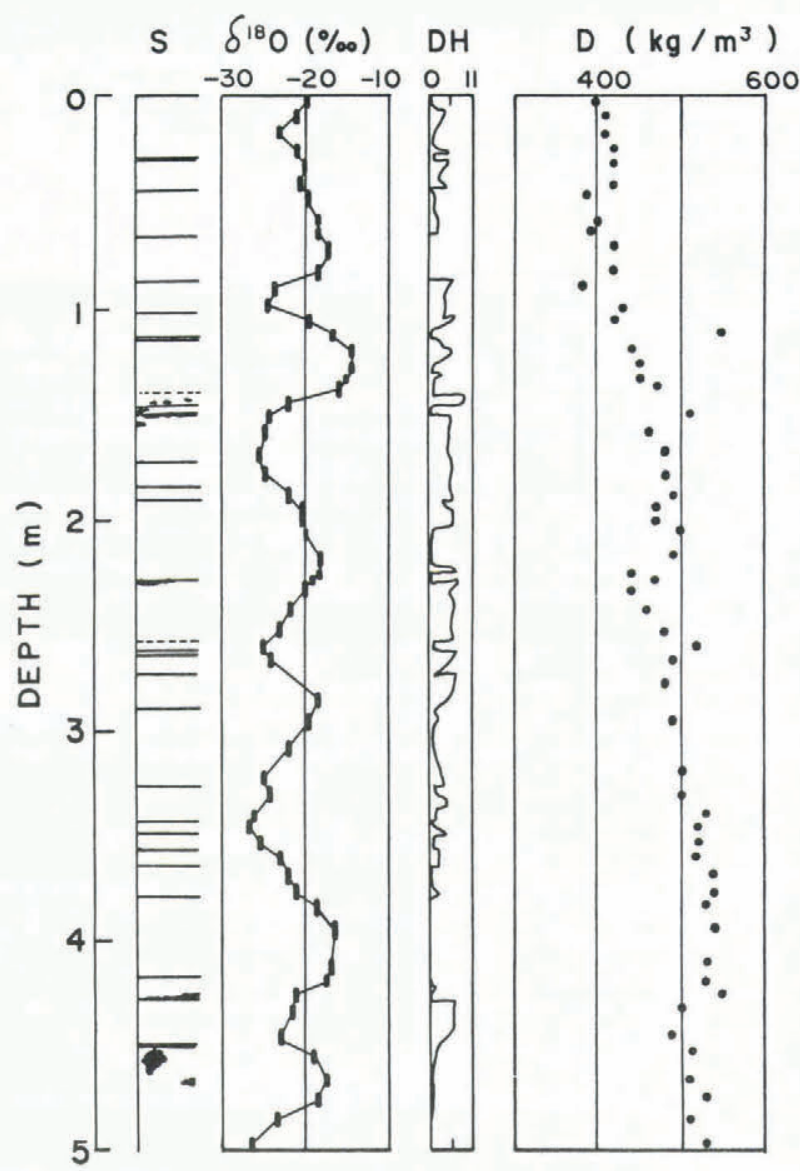

Fig.4. Vertical profiles of oxygen isotope composition $\left(6^{18} \mathrm{O}\right)$, depth hoar level $(\mathrm{DH})$ and density (D) in part of a $30 \mathrm{~m}$ core at S18, together with vertical profile (S) of stratigraphic elements.

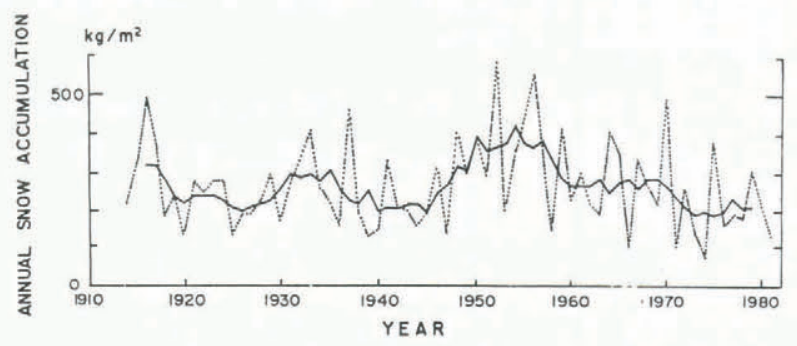

Fig.5. Variations of annual net accumulation from 1914 to 1981 (dashed line), based on the $30 \mathrm{~m}$ core analysis at S18. The solid line shows 5 year moving averages.

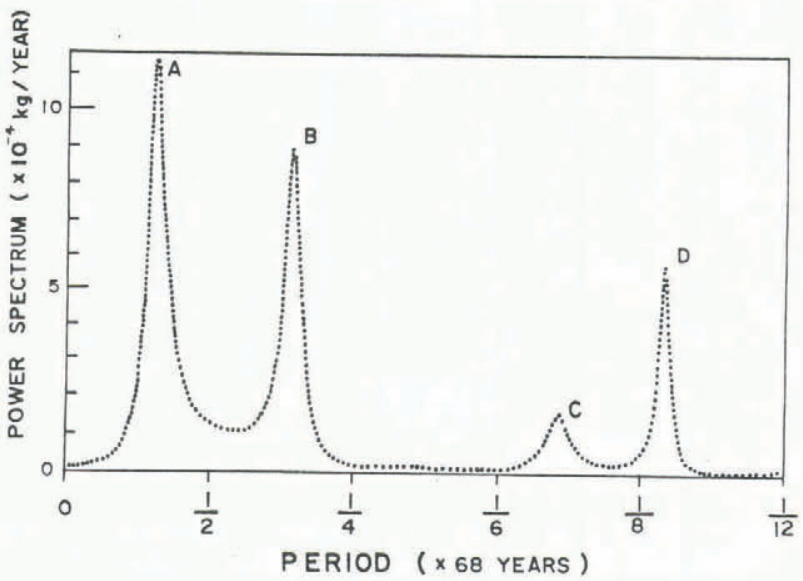

Fig.6. Power spectrum of annual net accumulations from 1914 to 1981 at S18, using MEM method. Peaks A, B, C and $\mathrm{D}$ indicate periodicities of 45 years, 18 years, 8.2 years and 6.7 years respectively. 
and winter reaches near $40^{\circ} \mathrm{C}$ (Satow 1978) and there frequently exists a strong temperature gradient near the surface. Actually the authors once measured the gradient to be $500^{\circ} \mathrm{C} / \mathrm{m}$ in snow, just near the surface, in winter. Here the effect of temperature gradient is considered as one explanation of $\delta^{18} \mathrm{O}$ profile-metamorphism of snow in the inland region.

Some models of $\mathrm{6}^{18} \mathrm{O}$ - metamorphism of snow with temperature gradient

Experiments were made to examine characteristics of $\delta^{18} \mathrm{O}$ profile changes of snow with temperature gradient. Each different temperature gradient was given vertically in a block sample, which was surrounded by thermal insulating materials. Figure 7 shows a schematic diagram of the experiment apparatus. The result of one such experiment is shown in Figure 8, where the snow sample dimensions were $0.15(\mathrm{~W}) \times 0.15(\mathrm{D}) \times 0.18(\mathrm{H}) \mathrm{m}$. After these experiments, developments of vertical snow texture were observed in most cases.

Based on experimental results under different conditions, the authors propose several models of metamorphism of $\delta^{18} \mathrm{O}$ profile with temperature gradient (Figure 9a and 9b). These models can be divided into two

\section{CONTROLLED COOL AIR}

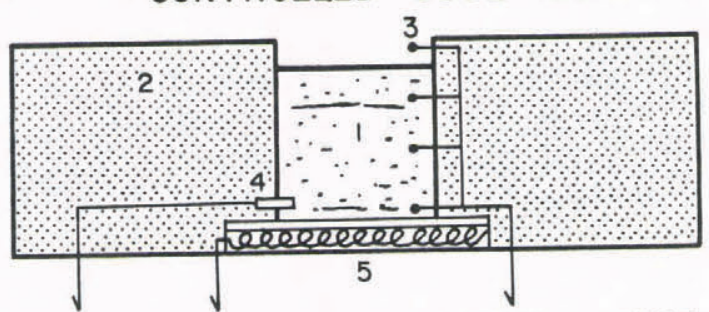

TEMPERATURE ELECTRIC CONTROL

SOURCE

\section{TEMPERATURE} RECORDER

Fig.7. Schematic diagram of experimental apparatus. 1: snow sample, 2: thermal insulating material, 3: thermometer, 4: thermal detector, 5: heater.

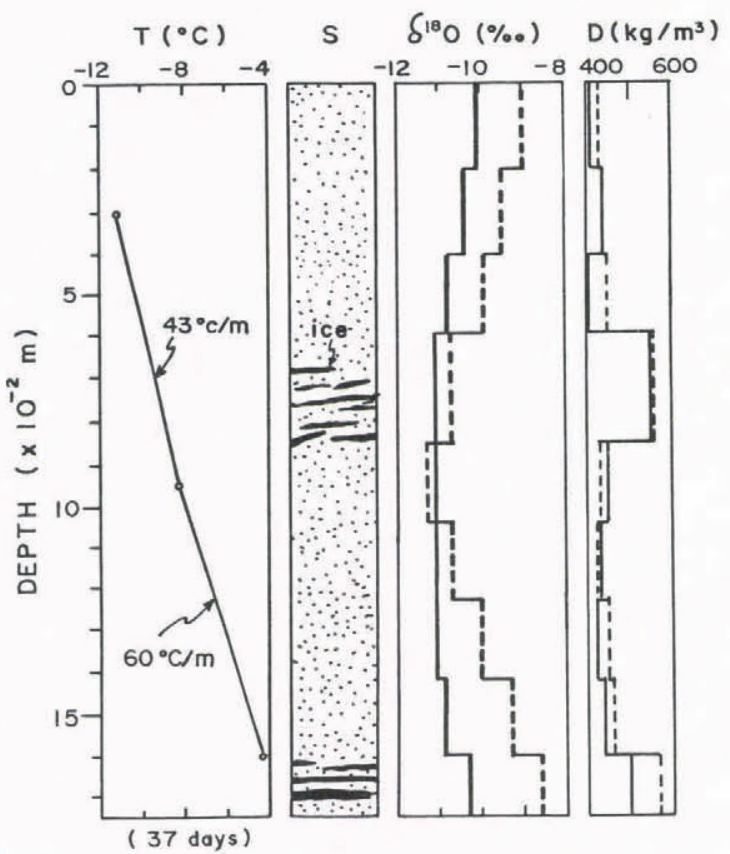

Fig.8. Result of one experiment concerning $\delta^{18} \mathrm{O}$ metamorphism of snow and temperature gradient for 37 days. $\mathrm{T}$ : snow temperature, $\mathrm{S}$ : stratigraphy, $\mathrm{O}$ : oxygen isotope composition $(\% \circ$ and $\mathrm{D}$ : density of the snow sample. Solid lines in diagrams of $8^{18} \mathrm{O}$ and $\mathrm{D}$ show values before the experiment, dashed lines those after the experiment.
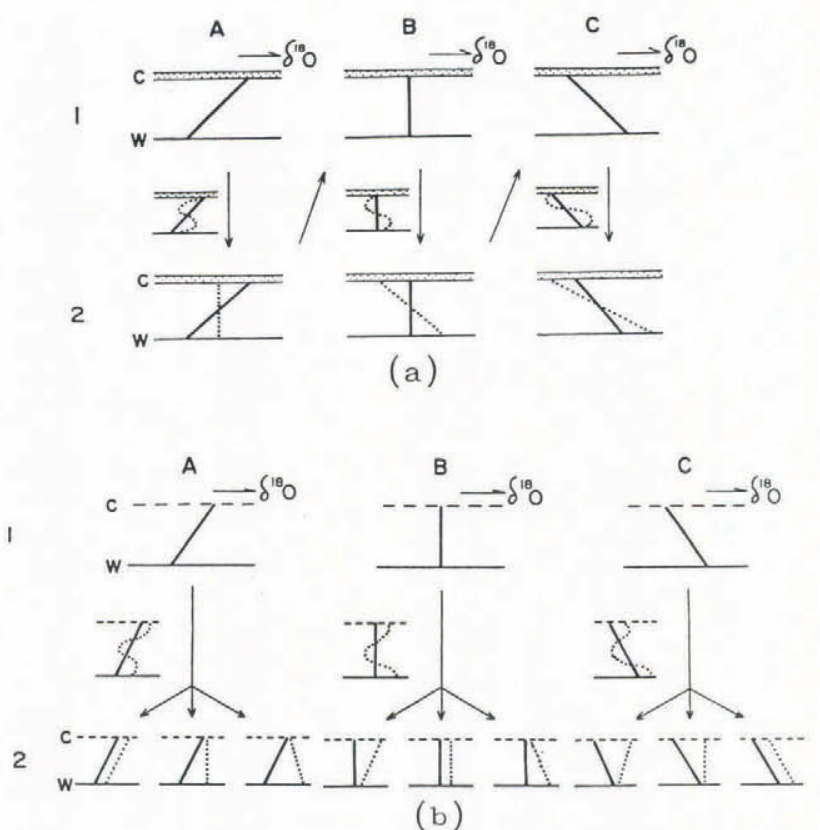

Fig.9(a). Metamorphism process model of $\delta^{18} \mathrm{O}$ profile of snow with temperature gradient under a cap. The upper side is colder and the under side warmer. Solid lines of $\delta^{18} \mathrm{O}$ profiles indicate the first profiles at initial stage 1 , dashed lines profiles at the next stage 2, of the metamorphism. 'A', 'B' and 'C' represent three different types of first $\delta^{18} \mathrm{O}$ profiles. (b) As for Fig.9(a), in uncapped snow.

groups: one with a cap, such as an ice crust or ice lense, and the other without. Figure $9 a$ and $9 b$ shows the speculated models under the condition that the upper side is colder and the underside is warmer. Which case of these models should be adopted to explain the actual $8^{18} \mathrm{O}$ profile-metamorphism depends on the circumstances of accumulation depth, strength of temperature gradient of snow, features of snow structures (density or porosity), etc. As mentioned above, the explanation of the $\delta^{18} \mathrm{O}$ profile of snow should be considered very carefully in regard to the $\delta^{18} \mathrm{O}$-metamorphism of snow with temperature gradient, especially of snow in the irregular accumulation zone and the low but uniform accumulation zone, with small accumulation, strong temperature gradient of snow and developments of hoar at depth.

\section{REFERENCES}

Hino M 1977 [Spectral analysis]. Tokyo, Asakura Shoten

(in Japanese)

Satow K 1978 Distribution of $10 \mathrm{~m}$ snow temperatures in Mizuho Plateau. Memoirs of the National Institute of Polar Research, Special Issue 7: 63-71

Satow K 1984 On the scatter of snow accumulation measured at a given place on the Mizuho Plateau. Memoirs of the National Institute of Polar Research, Special Issue 34: 132-136

Watanabe O 1978a Distribution of surface features of snow cover in Mizuho Plateau. Memoirs of the National Institute of Polar Research, Special Issue 7: 44-62

Watanabe O 1978b Stratigraphic studies of the snow cover in Mizuho Plateau. Memoirs of the National Institute of Polar Research, Special Issue 7: 154-181

Watanabe O, Kato K, Satow K 1981 Some results on oxygen isotope and stratigraphic analysis of firn in Mizuho Plateau, East Antarctica. Memoirs of the National Institute of Polar Research, Special Issue 19: 264-279

Yamada T, Wakahama G 1981 The regional distribution of surface mass balance in Mizuho Plateau, Antarctica. Memoirs of the National Institute of Polar Research, 